\title{
OS BAILES DE CHARME: ESPAÇOS DE ELABORAÇÃO DE IDENTIDADES JUVENIS
}

\author{
CARlos HenRIQUe dos SANTOS MARTINS*
}

\begin{abstract}
RESUMO
O Charme é uma manifestação cultural popular urbana hibridizada, específica da cidade do Rio de Janeiro. Os bailes realizados em diversos bairros são freqüentados, em sua maioria, por adultos. Trabalha-se com a hipótese de que esses espaços de lazer e sociabilidades sejam, também, freqüentados por jovens. Através da participação em muitos eventos, observa-se a presença de indivíduos jovens, que se encontram em grupos ou que surgem sozinhos. As conversas compartilhadas com alguns deles têm como objetivo compreender de que maneiras elegem o baile como espaço de elaboração de suas identidades a partir das relações estabelecidas com seus pares. $\mathrm{O}$ entendimento de que os bailes são, também, espaços intergeracionais é importante para perceber como são tecidas as relações entre jovens e adultos. Por último, identificam-se quais as contribuições que a presença juvenil e suas expressões culturais trazem para a continuidade do Charme, além de possíveis transformações que essa mesma presença pode produzir, e com isso, ressignificar esse movimento cultural.
\end{abstract}

Palavras chave: Sociabilidade, Juventudes, Cultura URbana

* Pesquisador do Observatório Jovem do Rio de Janeiro, Universidade Federal Fluminense, Rio de Janeiro, Brasil. Mestre em Educação pela Universidade Federal Fluminense. Professor do Ensino Fundamental (SME-RJ) e Médio (FAETEC). E-Mail: chlobo@ibest.com.br. 


\title{
LOS BAILES DE CHARME: ESPACIOS DE ELABORACION DE IDENTIDADES JUVENILES
}

\begin{abstract}
RESUMEN
El Charme es una manifestación cultural urbana popular hibridizada, específica de Río de Janeiro. Los bailes realizados en diversos barrios son frecuentados en su mayoría por adultos. Se trabaja con la hipótesis de que estos espacios de esparcimiento y sociabilidad sean también frecuentados por jóvenes. A través de la participación en muchos eventos, se observa la presencia de jóvenes, que se encuentran en grupos o solos. Las conversaciones efectuadas con algunos de ellos tienen como objetivo comprender de qué manera eligen el baile como espacio de construcción de sus identidades, a partir de las relaciones establecidas con sus pares. El entendimiento que los bailes son también espacios intergeneracionales, es importante para percibir cómo son tejidas las relaciones entre jóvenes y adultos. Por último, se identifican cuáles son las contribuciones que la presencia juvenil y sus expresiones culturales aportan para la continuidad del Charme, más allá de posibles transformaciones que esa misma presencia puede producir, y con eso, resignificar ese movimiento cultural.
\end{abstract}

Palabras Clave: Sociabilidad, Juventudes, Cultura uRbana

\section{THE DANCES OF CHARME: SPACES FOR ELABORATION OF YOUTH IDENTITIES}

\begin{abstract}
El Charme is a popular urban cultural manifestation developed specifically from Rio de Janeiro. The dances are carried out in diverse neighbourhoods and are performed, mostly by adults. It works itself with the hypothesis that these spaces of dissemination and sociability are also performed by youth. Besides being performed in many other events, youth are observed, wether in groups or alone. The conversations performed by some of them, act as an objective to understand by which way they choose the dance as a space to construct their identities, from the relations established with their peers. It is understood that the dances are also inter-generational spaces and are important because we can perceive the way in which relationships between youths and adults are formed. Finally, it is the contributions of the presence of youth, and their cultural expressions which are identified and they contribute to the continuity of El Charme, beyond possible transformations which this presence can produce, and with that, again signifies a cultural movement.
\end{abstract}

KEY WORDS: SOCIABILITY, YOUTH, URBAN CULTURE 
APRESENTAÇÃo

ENTRAR NOS DIVERSOS «MUNDOS juvenis» pelo caminho da cultura é um desafio bastante instigante para um pesquisador. Os jovens criam espaços próprios de sociabilidade que se transformam em territórios culturalmente expressivos nos quais diferentes identidades são elaboradas.

Nesse sentido, a cultura aparece como espaço social privilegiado de práticas, representações, símbolos e rituais que os jovens buscam para demarcar uma identidade. Na esfera cultural se processam sociabilidades, práticas coletivas e se põem em jogo interesses comuns.

Como se constituem os espaços de identidades juvenis nos circuitos dos bailes de Charme existentes na cidade do Rio de Janeiro uma vez que esses são freqüentados, na sua maioria, por adultos? Que elementos de cultura e juventude se constituem através do Charme?

Minha hipótese é que os territórios da cultura do Charme são configurados pelos adultos. Assim sendo, procuro indagar quais são os espaços de autonomia conquistados pelos jovens nesse contexto de (pré)dominância cultural adulta que permitem aos jovens elaborar as suas identidades e como as práticas juvenis transformam esses mesmos ambientes. Ou seja, a investigação parte da observação de que o Charme ocupa territórios construídos a partir de práticas instituídas pelos adultos, práticas essas que necessariamente não são as mesmas presentes nas culturas juvenis. Desse modo, cabe perguntar como são estabelecidas as relações intergeracionais em territórios ocupados pelos adultos que estabeleceram suas identidades junto com a arquitetura do Charme e os jovens que, estando presentes nesses mesmos territórios, buscam ressignificá-los a partir de suas práticas específicas. Sendo assim, torna-se necessário observar se há espaço para os jovens criarem novas práticas e, com isso, transformarem o ambiente do Charme em território de grupos de identidades juvenis.

Para responder a essas questões, parto da hipótese de que o Charme é uma manifestação da cultura popular urbana que, apesar de pouca visibilidade nas mídias, constitui-se em espaço de sociabilidades e elaboração de identidades, não só por parte dos adultos, mas também para os jovens. Tal proposição traz, ainda, uma outra questão importante: como a presença da juventude nos bailes contribui para a transformação do Charme a partir do diálogo entre a memória dos adultos que estão desde o início no movimento e os jovens charmeiros dotados de expressões culturais mundializadas pelas indústrias culturais? 
Este trabalho procura trazer o Charme para o espaço acadêmico e permitir àqueles que se interessem pelo tema participar da discussão a respeito dessa manifestação cultural carioca. Busca ainda apresentar novos/outros espaços de elaboração de identidades juvenis que podem estar invisíveis a todos os interessados pelos temas ligados à juventude.

A quase invisibilidade que o movimento Charme tem não só nos meios midiáticos, mas também nos meios acadêmicos, foi um dos aspectos que dificultaram a pesquisa. A importante contribuição do DJ Corello para a construção do texto referente ao Charme foi possível através das nossas conversas por correio eletrônico e durante os bailes.

\section{O CHARME SE APRESENTA}

Durante muitos anos freqüento os bailes, as festas e reuniões sociais em alguns bairros da cidade do Rio de janeiro em que é possível ouvir e dançar ao som de determinada música negra — ou black music, como os freqüentadores gostam de chamar-. A descoberta do Charme deu-se através de alguns amigos que, no início dos anos noventa, convidaram-me para um baile sob o viaduto Negrão de Lima, situado no bairro de Madureira. É claro que o convite soou estranho uma vez que não poderia imaginar o evento acontecendo em espaço público, improvisado, em que fosse possível estar em segurança. A crescente violência presente nas ruas da cidade marcada, principalmente, pelo descaso das autoridades com a segurança pública, assim como o conflito armado entre traficantes pelo domínio de determinados espaços tem feito com que, cada vez menos, as pessoas participem de atividades noturnas. A insegurança parece tomar conta de todos e provocar o esvaziamento dos espaços públicos.

Foi no ambiente democrático da rua que pude estabelecer as primeiras relações de identificação com a musicalidade característica do movimento Charme, uma vez que diversas canções povoaram o universo da minha juventude. Naquele período, o que hoje é denominado Charme, estava de certa maneira bem separado: músicas de discoteca, black music, soul e swing. Para cada estilo musical havia um público específico, um modo peculiar de ser que muitas vezes se representava não só no gosto musical, mas também na dança, no estilo de vestir e no próprio comportamento. O Charme é uma construção feita a partir da música negra norte-americana. Sua origem, mantendo a especificidade do regional, tem como ponto de referência o Rythm\&Blues cuja dinâmica global foi possível graças à mundialização da cultura esta- 
dunidense promovida pelo domínio e expansão dos seus meios de comunicação. Assim, a dimensão global da black music como produto expressa-se, no caso do Brasil e, mais especificamente, no do Rio de Janeiro, através do caráter local que o Charme traduz, resultado que é de contaminadas ressignificações próprias da cultura urbana carioca.

A familiaridade com a música, alguns cantores — verdadeiros ícones de algumas gerações que a memória trazia para o presenteas coreografias - algumas conhecidas, outras com alto grau de dificuldade e elaboração - o que parecia revelar a presença de grupos específicos de dançarinos que treinavam para aqueles momentos, formaram os ingredientes necessários para que houvesse a imediata identificação com esse movimento, com os bailes dos quais me tornei participante e freqüentador assíduo.

A afetividade, a forma gentil e carinhosa com que sempre fui recebido pelos charmeiros aumentaram o meu interesse em continuar presente nos muitos eventos que ocorriam pela cidade. Se no início eu poderia considerar-me um elemento estranho àquele universo, hoje me sinto totalmente inserido em seu contexto. A cada festa surge um novo convite, novos amigos. Em cada baile os DJs anunciam os próximos eventos que preenchem a «agenda do Charme» até para os meses seguintes. A dificuldade é dar conta de cumprir a agenda de compromissos sociais que oportunamente transformei em roteiro de pesquisa acadêmica.

É nesse «mundo» que considero complexo em relações interpessoais pautadas na amizade, no afeto, na alegria, no prazer e no festejar que se tornou possível pesquisar a presença de grupos juvenis que elaboram as suas identidades a partir do Charme.

\section{CULTURAS E IDENTIDADES JUVENIS: POR QUÊ?}

A diversidade de práticas culturais dos jovens caracteriza-se não só pelas expressões específicas de cada grupo, mas também pelos diferentes olhares que traduzem variadas formas de dizer tais culturas. Além disso, existe o fato de que as mesmas se afirmam na necessidade de contraporem-se à existência de culturas não juvenis que parecem querer interditar os espaços de expressão para os jovens. Geralmente essas são as culturas instituídas ou preservadas por instituições de poder.

A pertinência da investigação traduz-se pela acentuada importância que a cultura apresenta como campo de possibilidades «de práticas coletivas e de interesses comuns, sobretudo em torno dos diferentes 
estilos musicais» (Sposito, 1999:7). De acordo com a referida autora, há «uma inquestionável motivação dos jovens em relação aos temas culturais em oposição ao seu afastamento das formas tradicionais de participação política» (Sposito, 1999:7). A música —elemento importante da cultura juvenil- apresenta-se assim, como aglutinadora de sociabilidades e, por isso, permitiria aos jovens a possibilidade de participação e atuação efetiva nas questões relacionadas com a sua comunidade e, como interlocutores, «com alguns segmentos da sociedade civil» (Sposito, 1999:7).

Marilia Sposito lembra ainda que é preciso admitir a existência de significativa diversidade de práticas coletivas entre os jovens, ainda pouco visíveis e escassamente investigadas. É nesse espaço de invisibilidade social que escolhi o Charme como objeto de interesse e estudo das formas de participação juvenil.

Os diversos processos de humanização são desenvolvidos em vários espaços sociais. Acredito que os jovens precisam ser compreendidos em uma perspectiva que «permita a construção de um olhar mais alargado sobre a educação como processo de humanização que inclua e incorpore os processos educativos não-escolares» (Gomes, 2002:1). Assim, foi possível eleger os bailes de Charme e seus diversos territórios como uma expressão da construção de um objeto de investigação educacional.

\section{A CENA CARIOCA É ALTERADA COM MUITO CHARME}

O Charme pode ser considerado a mais perfeita hibridização, ${ }^{1}$ da cultura popular internacional urbana resultante dos vários segmentos da música negra que deram suporte ao movimento Black Rio nos anos 70. Sua denominação - Charme - deve-se ao DJ Corello que atribuiu esse nome em função das expressões corporais típicas das coreografias em decorrência do R\&B - estilo musical mais melódico e cadenciado-. Embora seja resultado da hibridização de diversos ritmos negros estadunidenses, o Charme só é conhecido com esse nome no Rio de Janeiro.

1 Canclini (2000:19) compreende hibridização como resultado de diversas mesclas interculturais, termo que abrange outros usualmente empregados, tais com mestiçagem e sincretismo. Segundo ele, esse termo «permite incluir as formas modernas de hibridação e supera as referências feitas geralmente a fusões religiosas ou de movimentos simbólicos tradicionais»». 
Os anos setenta foram marcantes e significativos para a gestação do Charme quando, embalados pelo soul, surgiram diversas equipes de som que marcaram esse período devido ao nascimento do Movimento Black Rio, no qual o soul conquistou seu espaço através de suas principais equipes: Soul Grand Prix, Mr. Funk Santos, Black Power, Dynamic Soul, Alma Negra e Leyzer. Os bailes na cidade eram animados por essas e outras equipes em diversos clubes, o que não só difundiu rapidamente o novo jeito de ser, como também atraiu enorme parcela da juventude popular carioca para esses espaços de diversão e sociabilidades. Porém, os mesmos eram divulgados, principalmente, com o apelo da presença das equipes e seus proprietários, colocando o trabalho dos DJs quase que em segundo plano.

Desse modo, ao compreender que era apenas mais um a animar, a tocar nos bailes e ao constatar que a equipe tornava-se mais importante do que o seu trabalho, Corello começou a flertar com outros ritmos como possibilidade de superar cada vez mais a qualidade de suas apresentações. Isso não significou, em um primeiro momento, o rompimento com o soul, apesar de observar que a evolução da produção musical não era acompanhada pelas formas de dançar, pelas coreografias características do movimento (esse fato pode ser observado até hoje).

O início do flerte abre as portas para outros sons - em especial o som da Philadelfia - e permite a aquisição de muitos e diferentes discos (LPs) que possibilitaram, não só aumentar a sua já riquíssima discoteca, mas despertar o seu interesse pelo estudo dos sons que ainda eram desconhecidos do grande público. Por isso a consideração de que aquele ainda não era o momento apropriado para que esses ritmos e melodias fossem apresentados nos bailes. Esse movimento começa a perder força por volta de 1976, com a crescente presença da discoteca, movimento musical mundializado pela força da indústria cultural, cujo marco inicial é o filme «Os embalos de sábado à noite». ${ }^{2}$ Segundo Corello, o soul,

como era um movimento multirracial, alguns brancos que freqüentavam, começaram a se interessar por outros ritmos, por outras levadas. Daí sur-

2 Esse filme arrastou multidões pelo mundo inteiro e seu principal apelo deve-se à sensualidade com que as coreografias eram apresentadas por John Travolta. Este ator representava uma personagem pobre que alcança a fama e o sucesso ao sair-se vitorioso nos maiores concursos de dança estadunidenses. A identificação com a personagem fez com que o movimento disco club, próprio de uma cultura local, fosse rapidamente globalizado pelas indústrias do cinema e da música. 
giu a divisão entre brancos e negros na dança coletiva. Nascia, assim o segmento cocota para a garotada branca (e alguns negros também) e que agregava outro visual diferente dos blacks.

A identificação com o movimento das (dos) cocotas, juntamente com a «febre» da discotèque, provocou o esvaziamento dos bailes de soul. Apesar disso, Corello continuou tocando esse ritmo musical até 1977 quando recebeu um convite para fazer parte da equipe do «Luizinho Disc-Jockey Soul». No ano seguinte, foi trabalhar com a equipe «PopRio» que já havia incluído o som característico da discotèque em seu repertório. Esse período é apontado por ele como marcante, pois ocorre não só a extinção de diversas equipes, mas também a transformação/adaptação de outras às mudanças no cenário musical provocadas pela influência dos meios massivos e da indústria cultural. Isso acarreta o início de um processo de hibridização musical, uma vez que se tornou possível ouvir e dançar, em um mesmo baile, o soul, a disco-music (que posteriormente evolui para a disco-funk), enfim, o que viesse e atendesse ao gosto dos vários freqüentadores.

Foi durante o período em que Corello trabalhava na equipe «PopRio», no final dos anos 70, que ocorreu a hibridização musical resultante da «raiz do soul» com a discoteca, ou seja, não havia um ritmo que pudesse ser característico daquele momento, uma vez que o primeiro estava pouco presente no gosto popular e o outro estava em franca decadência que se acentuou em 1980. Essa indefinição musical proporcionou alguns desdobramentos, uma vez que os DJs não tinham clareza dos caminhos a seguir. Alguns optaram pelo Disco-Funk (posteriormente, Funk Melody) e Corello direcionou o seu trabalho para o Rythm\&Blues (R\&B).

No início de construção do movimento charmeiro, não era possível para o DJ perceber a possibilidade desse estar sendo formado a partir da junção de diversos ritmos e estilos. Para ele, isso ocorreu posteriormente, devido ao seu crescente interesse pelo jazz. A «quase obrigação inicial» de selecionar e apresentar os cantores e cantoras que se aproximavam da «linha disco» é justificada por ele como «necessidade do mercado», ou seja, era preciso manter os bailes com grande freqüência e isso somente se tornava possível a partir da execução de um repertório conhecido e identificado com/pelo grande público presente. Porém, isso não o impedia de introduzir nas seqüências musicais algumas faixas nas quais «esses mesmos artistas cantavam o R\&B da época». Não podemos esquecer que a indústria cultural estadunidense e os meios midiáticos 
disponíveis deram uma dimensão global ao movimento da discoteca. Além dos filmes e novelas, pôde-se observar a enorme quantidade de cantores, cantoras e bandas - como, por exemplo, Michael Jackson e Earth Wind \& Fire - que, embora em alguns casos efêmeros, alcançaram o topo das paradas de sucesso em todas as rádios do mundo, permitindo que a indústria fonográfica atingisse marcas de vendagem consideradas quase insuperáveis em sua história.

Nesse período, Corello animava os bailes do Clube Mackenzie e em determinado momento reservado às músicas mais lentas e melódicas, propôs-se a apresentar ao público algumas músicas que costumava ouvir em casa durante seus momentos de lazer ou quando da seleção musical que comporia o repertório do seu trabalho como DJ nos bailes. As músicas que pretendia mostrar tinham como base o R\&B. Pela dificuldade de pronúncia e pela falta de apelo entre os freqüentadores, havia a necessidade de substituir a expressão por alguma palavra que pudesse aproximar-se e traduzir a sensualidade e o charme necessários para dançar o r\&b. Durante uma de suas apresentações, ${ }^{3}$ para anunciar tais músicas, em sua maioria desconhecidas, Corello, ao microfone, introduziu a seguinte frase: «chegou a hora do charminho, transe seu corpo bem devagarzinho». Apesar de considerar o texto impróprio ou de linguagem ultrapassada para o momento atual, foi essa frase que, segundo ele, deu origem ao Charme. Esse movimento, com o passar do tempo, irá consolidar-se pela influência não só do jazz, como também do soul e do raggamuffin. ${ }^{4}$ Além disso, a expressão «Charme» relaciona o termo à possibilidade de melhoria da auto-estima do negro que poderia ser revelada na mudança em seu comportamento e na importância dada ao «vestir melhor». Os bailes estão, assim, povoados pelo imaginário social que exprime a possibilidade de valorização da cultura negra, traduzida pela música, pela dança e pela elegância em vestir-se.

Com relação à terminologia utilizada, Ribeiro (2000:6) afirma que

A incidência de nomes em língua inglesa traduz a marca da identidade negro-americana, característica do Charme. Sem a preocupação do modismo, trata-se de uma estratégia (talvez não consciente de uso de termos

3 No dia oito de março de 1980, quando a equipe de som Pop-Rio fazia sua estréia no Esporte Clube Mackenzie, no bairro do Méier, Rio de Janeiro.

4 Estilo musical híbrido que inclui o reggae e o rap. É caracterizado por ritmos mais acelerados através da utilização de novos equipamentos musicais de alta tecnologia. 
positivados), a fim de neutralizar os termos carregados de significado negativo em nosso idioma. Por exemplo, o termo black é mais positivado do que «negro» ou «preto».

Observamos, assim, que esse movimento musical surgido no Brasil nos anos oitenta, cujo nome está relacionado ao $R \& B$, ao Soul e à Black Music, apresenta-se carregado de expressões musicais que parecem estar ligadas ao movimento negro estadunidense que lutava (e luta [!]) pela igualdade de direitos dos afrodescendentes daquele país. Este movimento - liderado pelo Black Power cujos representantes mais conhecidos eram os ativistas dos «Panteras Negras» que lutavam de forma radical pelo reconhecimento da cidadania dos afroamericanos - teve grande repercussão em todas as comunidades negras dos diversos países do mundo e, aqui no Brasil, parece também ter se transformado em marca de identidade de tais comunidades.

\section{IDENTIDADES E TERRITÓRIOS}

O Charme parece traduzir uma linguagem que permite aos negros brasileiros, ${ }^{5}$ pistas de identificação com a cultura dos afrodescendentes americanos. Isso ocorre através da relação e, até mesmo, da semelhança com os problemas sociais pontuados por formas de exclusão social e possíveis respostas manifestadas em formas de luta e resistência. O ritmo, a melodia e, em alguns casos, a origem social dos cantores podem revelar a unidade do sentimento de injustiça e desigualdade, mas ao mesmo tempo servem de estímulo à formação dos grupos de identidade.

As identidades são, portanto, complexificadas em espaços específicos - muitas vezes desprestigiados e ignorados pelo poder público- por intermédio da cultura local ou regional, atravessada pelos meios e mediações do global. Sendo assim, é importante pensar como cada grupo se apropria das possibilidades restritas de acesso aos meios massivos para expressar sua cultura, sua voz e transformá-las em presença. A cultura urbana é configurada de acordo com as diferentes maneiras com que os grupos a utilizam para unir «seus próprios instrumentos culturais, os da cultura letrada e os dos meios de comuni-

5 Não existe, nessa expressão, qualquer intenção de determinar o gênero, visto que todos participam, independente dessa condição. Apenas a utilizo como forma de simplificar o entendimento a respeito daquilo a que quero fazer referência - os homens, as mulheres, os jovens e as jovens de origem africana que compõem a mestiçagem brasileira-. 
cação» (Sarlo, 2000:109). Ou ainda, como os grupos produzem e veiculam o cultural que os traduz como sua «marca registrada» e os transformam em estratégia de luta nos seus espaços específicos, pois sabem que «se quiserem ser ouvidos na cidade, devem usar os mesmos meios pelos quais eles ouvem o que se passa na cidade» (Sarlo, 2000:101).

Esses processos de elaboração, ou mesmo de reelaboração são desenvolvidos a partir de uma dinâmica popular que mobiliza a participação nos meios audiovisuais e que leva à construção de espaços alternativos e, desse modo, ao surgimento de novos atores sociais. ${ }^{6}$ São essas construções/reconstruções identitárias que podem favorecer mudanças nas estruturas econômicas, políticas e sociais através de constantes pressões desses sujeitos organizados a partir do cultural, para a participação nas decisões que dizem respeito à melhoria de sua qualidade de vida e inserção social. A identidade deixa de ser silenciosa, ela é expressão, tem voz e quer vez.

O movimento parece encontrar a sua força, os seus espaços de consolidação em alguns lugares das periferias da cidade, nos quais há uma grande concentração de negros e/ou pobres. O subúrbio apresenta-se como o local do Charme. São esses bairros que eu tenho freqüentado por alguns anos com o objetivo de localizar o que considero melhor e mais original naquilo que diz respeito às dimensões artísticas, culturais e afetivas do Charme. Assim, é possível encontrar hoje os bailes regulares, ou seja, aqueles que permanecem em seus locais de origem, tais como o Point Chic Charm, realizado há cinco anos, aos domingos, em uma rua do bairro carioca de Padre Miguel, o Botequim do Charme que acontece às sextas-feiras, desde 1999, no bar do Bill, na Cidade de Deus e o Charme Bola, realizado há nove anos, sempre às quintas-feiras, no Cordão do Bola Preta, no Centro da cidade. Existem os bailes mensais como o Flash Back do Clube Mackenzie do Méier, realizado sempre no primeiro sábado de cada mês e o Tangará, bar situado na rua Álvaro Alvim, no centro da cidade. ${ }^{7}$ Existem, ainda,

6 Existem, por exemplo, muitas rádios comunitárias de grande abrangência territorial que transmitem programas de Charme, funk e pagode que mobilizam milhares de ouvintes no Rio de janeiro.

7 O bar está situado em um prédio que passa por reformas. O nome ficou como referência ao local onde o baile teve o seu início, na década de 90. De acordo com o DJ Wilton, responsável pelo Charme, é possível que, ao final das obras, o bar não mais exista mais. 
os bailes de caráter esporádico que geralmente são promovidos para comemorar o aniversário de alguém da comunidade charmeira do lugar onde a festa ocorre ou mesmo de um DJ. Em alguns locais é cobrada a entrada, o que muitas vezes e, dependendo do dia do mês, torna inviável o ingresso para alguns de seus participantes. A gratuidade e a própria localização de determinados bailes - a rua ou o botequim-é garantia de casa cheia todas as semanas.

Nesse universo, é possível identificar outras dimensões para além do conformismo ou da resistência, visto que «o baile de Charme é uma manifestação típica do Rio de Janeiro que se constitui, considerando, inclusive, a sua condição de ambiente de lazer e de entretenimento, em núcleo gerador de diversos espaços sociais» (Ribeiro, 2000:2).

Transitar pelos diferentes territórios possibilita uma diversidade de opções de lazer além da certeza de entrar em um mundo mágico povoado por sujeitos dispostos a, através da música e da dança, consolidar espaços de sociabilidades. O espaço não está restrito aos moradores mais próximos, pelo contrário, resulta da mobilidade e facilita, através da diversificação, a ocupação da cidade. Estar a cada dia em diferentes lugares permite ao charmeiro estabelecer vínculos de afetividade e relações de pertencimento ao espaço urbano.

A localização do baile, assim como as oportunidades que cada jovem possui de circular pela cidade - ou até mesmo de não circular - nos remetem às categorias «na vizinhança» e «fora da vizinhança» (Magnani, 2000). Alguns jovens valorizam a realização de bailes nas proximidades de suas residências como oportunidade de acesso a uma das poucas formas de lazer em função da quase ausência de equipamentos públicos ligados a esse setor. Além disso, as constantes interdições resultantes da violência, da falta de transportes e do desemprego parecem fortalecer a importância desses eventos.

Outros jovens, além de freqüentar os bailes na vizinhança, conseguem transitar por outros espaços fora dela, o que lhes permite ampliar os seus trajetos. Isso ocorre pelo fato de que alguns não estão sujeitos às limitações impostas pelas questões apontadas acima e por terem relação com o local onde moram e com as suas condições econômicas. Para alguns jovens, significa, ainda, libertar-se de «uma determinada forma de controle» dos moradores que se conhecem (Magnani, 2000:32).

Para os jovens charmeiros que circulam pelos diferentes bailes realizados fora da vizinhança, a oportunidade de encontrar outros jovens de pedaços diferentes não representa a cautela supostamente 
necessária na relação com outros grupos. Apesar de saberem que estão fora de seu pedaço, também sabem que o baile de Charme não representa espaço de conflitos e hostilidades, mas de oportunidades de tecer novas redes de sociabilidades com jovens de outros pedaços da cidade. Nesse caso, o baile não corresponde «à idéia tradicional de pedaço», uma vez que,

aqui os freqüentadores não necessariamente se conhecem - ao menos por intermédio de vínculos construídos no dia-a-dia do bairro-, mas sim se reconhecem enquanto portadores dos mesmos símbolos que remetem a gostos, orientações, valores, hábitos de consumo, modos de vida semelhantes (Magnani, 2000:39).

\section{DIVERSIDADE DE ESTILOS}

Os grupos juvenis são coletividades que, de maneira geral, tomam como referência para a elaboração de suas identidades e como condição de pertencimento ao grupo um estilo que elabore, além de uma proposta estilística, um modelo de comportamento. O estilo é resultado de elaborações coletivas e aceito consensualmente como modelo substantivo. Desse modo, os grupos recorrem a uma linguagem visual e/ou musical que os substancia. Podem ser resultado de culturas de consumo ou de práticas contraculturais — underground- (Kemp, 1993).

Esse foi um dos muitos aspectos observados durante as conversas que eu tive com os jovens durante os bailes em que realizei a pesquisa. A questão do estilo mereceu destaque nesse texto, não só por conta de sua recorrência entre os jovens entrevistados, mas também por ser uma marca identitária que parece destacar os charmeiros de maneira geral.

A possibilidade de transitar em diversos espaços de charme permite ao Pedro, um dos entrevistados, ser diverso na elaboração de seu estilo pessoal. Para muitos jovens, ser «camaleão» é transitar por diversos estilos sem, necessariamente, estar preso a apenas uma forma de identificar-se com um único grupo. Isso também não serve como passaporte para a entrada nesse terreno. É possível transitar por diversos grupos de estilo e para cada um deles apresentar-se de acordo com a sua forma particular de ser.

Os referenciais simbólicos específicos da juventude são sistematicamente potencializados pela indústria cultural para, ao direcionar o consumo, reconstruir e reconfigurar de forma contínua o sujeito juvenil. Este, por sua vez, identifica-se no grupo e com o grupo pela quan- 
tidade e qualidade dos signos específicos relacionados ao poder e a posse dos objetos emblemáticos que, por sua vez, funcionam como passaporte para a entrada em determinado grupo. A autorização para o acesso ou mesmo para a constituição de grupos identitários não se limita aos referenciais estabelecidos pela indústria como sendo específicos dos jovens. Porém, esses funcionam como mediadores para o encontro dos iguais que se diferenciam dos outros. Cada grupo juvenil possui, assim, marcas visíveis que o caracterizam e unificam, mas que o diferencia de outras juventudes.

A capacidade de transformação do jovem e de acordo com o grupo ou com o ambiente não significa conflito de personalidade, mas competência de adaptação aos diversos contextos onde estiver inserido mesmo que temporária ou transitoriamente. Assim, ser camaleão é ter a possibilidade de constituir múltiplas identidades.

A circularidade permite a distinção de estilos. Isso não impede que em um mesmo espaço haja diversidade de grupos e até mesmo de gerações. O Viaduto de Madureira, por exemplo, Pedro observa que é um espaço onde,

tem a galera do hip hop e tem a galera do charme. Porque ali quando toca Charme, a galera do Charme vai para o meio da pista e começa a fazer os passinhos. Vou dizer [...] os coroas, né [!]. Meu pai, o Zezinho [...] os coroas no bom sentido, né [!]. E na hora do hip-hop fica aquela rodinha ali. $\mathrm{O}$ estilo de roupa também muda.

Segundo ele, os grupos são facilmente identificáveis também pelo vestir, uma vez que o «cara do Charme, ele vai social, ele vai arrumado». Ressalta, porém, que o estilo social está atualizado, não tendo relação com «o social de antigamente, é um social largado».

Largado, significa, nesse caso, cuidadosamente desalinhado. Há esmero por parte dos jovens em criar um estilo próprio e bem elaborado através de marcas características do estilo, mas pontuada por particularidades que estão relacionadas a interpretações, a releituras pessoais desse mesmo estilo. Assim, o lenço, por exemplo, pode estar amarrado de diversas formas, não só na cabeça, como também em muitas outras partes como o braço, o punho, a coxa e os tornozelos. Esse mesmo adorno, um dia andou pelos pescoços dos cascudos de hoje que foram jovens dos anos oitenta.

Há um cuidado maior em vestir-se de forma a combinar a roupa sem chamar muito a atenção ou sem a utilização de adornos. Por outro lado, os jovens característicos do hip-hop e que também dançam 
Charme parecem traduzir a influência desse movimento cultural mundializado na cultura charmeira do Viaduto. Esses grupos usam como adornos os lenços, mochilas, camisas de equipes de basquete da NBA e calças muito largas — geralmente com a numeração acima de seus manequins-. Dentro da mochila, que serve para compor o estilo, é comum encontrarmos apenas o pente e a bandana. Para os dançarinos que rodam no chão, é possível transportar, ainda, uma camisa e um desodorante, pois, de acordo com Pedro, «pra mulherada tem que ter um cheirinho bom».

A singularidade estilística que em determinados lugares serve como possibilidade de identificar-se e permite ser aceito, em outros pode servir para desenvolver reações muitas vezes preconceituosas por parte de alguns adultos. Isso pode caracterizar um rompimento, ou melhor, descontinuidades nas relações intergeracionais à medida que os bailes passam a ser rotulados segundo alguns aspectos. Para alguns adultos, parece haver espaços específicos para a presença juvenil. De alguma forma, eles tentam restringir a circulação dos jovens nos diversos espaços de lazer existentes na cidade através de argumentos pouco convincentes. Estes podem variar entre o «estilo diferente», o desalinho do traje em desacordo com determinado baile até o tipo de músicas que tocam no mesmo. Ou seja, a música não está apropriada, pois para muitos adultos, o jovem de hoje só curte ouvir e dançar hiphop. Observamos que, apesar de ser verdade em parte, isso não deve ser generalizado nem servir de elemento constrangedor da liberdade de transitar pelos bailes. Há muitos jovens que gostam e estão inseridos na cultura de consumo do hip-hop.

Mas há outros estilos marcantes e que podem expressar múltiplas identidades: o som — estilo musical — pode aproximar muitos e diferentes jovens sendo, desse modo, uma das possibilidades de elaboração de identidades. Porém, nesses mesmos bailes, há jovens que, apesar de identificados pela e com a música, elaboram suas identidades também por diferentes possibilidades de se vestir que são distintas daquelas presentes no hip-hop. O que estou dizendo é que o ritmo musical que predomina em alguns bailes pode determinar certa predominância do estilo juvenil expresso no vestuário específico, mas não inviabiliza outras possibilidades de se vestir. Assim como há bailes específicos de hiphop, onde essa expressão cultural está marcadamente presente, há bailes exclusivos de Charme onde outros estilos são facilmente observados. Os jovens vestem-se de acordo com o lugar e com as suas relações de consumo junto à indústria cultural orientada pela mídia. 
Há bailes de Charme nos quais é possível notar a diversidade de estilos. Além do hip-hop, há jovens, como Marcelo, que se vestem em um estilo mais casual, menos despojado. Segundo ele, há certos bailes em que «o pessoal vai lá pra manter ainda o estilo da época, o estilo flash back, com aquele cuidado». Para cada baile há um estilo que predomina. Embora encontremos o terno e a gravata, hoje os freqüentadores o estão abolindo, sem deixar de lado a preocupação com o traje, pois este faz parte do ritual. Mesmo os jovens têm essa preocupação:

sempre quando eu vou (aos bailes de flash back), eu procuro ir social, uma calça social, um sapatinho quadradinho, camisa de pano, um blusão, né. Não gosto muito de usar mangas compridas, não. Um blusão aqui assim, por fora mesmo. É muito raro eu usar camisa por dentro. A vestimenta, às vezes eu uso conforme, às vezes, não.

Além de destacar o estilo e suas diversas expressões como possibilidade de marcar múltiplas identidades relacionadas ao ritmo musical e aos territórios, Marcelo destaca os bailes como espaços de sociabilidades em que é possível encontrar «aquela galera, ${ }^{8}$ tranqüila que sabe lidar com o outro, que gosta realmente da música, tem aquele envolvimento, sabe fazer aqueles passinhos»»,

Suas redes de amizades são tecidas através das possibilidades de circular por diversos bailes e encontrar pessoas. Sua fala parece sintetizar esse aspecto:

Eu me sinto bem freqüentando o baile de Charme. É um estilo de música que me agrada muito. Me sinto em casa em todo o lugar que toca Charme. Pra mim, eu tô na minha casa. De todos os estilos de música que eu já ouvi é o que mais me identifiquei, então, freqüento com o maior prazer. E, além disso, é uma grande amizade, a gente faz um grande vínculo de amizades.

8 Marcelo utiliza esse termo apenas para designar o seu grupo de identidade. Para Herschman (2000:78), «hoje [...], o termo faz parte do vocabulário juvenil e não juvenil da cidade e, em geral, é utilizado também para designar uma multidão».

9 A memória-lembrança dos bailes, do auge da juventude charmeira dos anos oitenta permite que a memória-hábito seja manifestada no presente através das coreografias, resultado das ações corporais incentivadas pela música, pela melodia. Dançar é um hábito que resulta de ações guardadas na memória e que se traduzem através da lembrança. 
Isso reforça uma das principais características do baile de Charme como espaço de afetividade e de relações de camaradagem. É certo que o seu primo teve papel de destaque quando da sua inserção nesse universo, pois possibilitou os primeiros contatos com outros jovens. Foi através dele que Marcelo conheceu a «galera», já que «ele é muito popular, conhece gente de todo lugar». Atualmente, possui a sua própria «galera» que demarca um território próprio onde se reúnem no baile: «tem um lugar que a gente combina. A gente fica sempre naquele mesmo lugar, na mesma posição. Toda vez já sabe que é ali».

Essa demarcação territorial com fronteiras invisíveis para quem não faz parte do grupo não significa que as mesmas não sejam intransponíveis. Ao contrário, elas aparentam estar sempre abertas, pois «há o pessoal do baile que chega, fala com a gente, fica, passa, sai, depois volta de novo». Esse jogo verbal traduz o intenso movimento do baile e as possibilidades de circular por diversos territórios a fim de fortalecer e ampliar as redes que intercomunicam esses mesmos territórios. «O que importa é todo baile você ser apresentado a alguém».

\section{a) A presença feminina}

Os grupos de identidade podem, aparentemente, conter uma certa unidade através do estilo, da música, de determinados interesses comuns. $\mathrm{Na}$ verdade, é uma unidade que reúne múltiplas identidades. Assim também é a juventude. A pluralidade de formas de ser jovem na atualidade supera a simplificação com que determinados meios de comunicação interpretam apressadamente a categoria social da juventude (Sposito, 1999).

Funkeiras, roqueiras, pagodeiras e charmeiras. Patricinhas, «largadonas rebeldes» e sociais. Tênis e salto alto. Certas expressões culturais e, especialmente nesse caso, musicais - funk, pagode, rock e Charmepodem nominar algumas «etiquetas no mundo das subculturas juvenis» que diversificam a cena juvenil na atualidade (Feixa, 2000).

O grupo de dança Everybody Dance é composto de oito jovens que expressam essa diversidade. Algumas delas trazem consigo marcas específicas de cada uma dessas etiquetas. O piercing, o salto alto e a maquiagem podem apresentá-las em suas individualidades. O que as unifica? «O Charme, o street Charme, o street hip-hop», ${ }^{10}$ responde Kelly.

10 Essas duas últimas expressões me foram apresentadas, pela primeira vez, durante a nossa conversa. Pode ser o equivalente ao «New Char- 
Diferentes de outros grupos juvenis para os quais o estilo de vestir é um aspecto fundante do próprio grupo e da identidade de seus integrantes, essas jovens consideram que se reunir para ensaiar novas coreografias ou para fazer apresentações em alguns espetáculos é o que realmente as identifica. Além disso, o gosto em comum por alguns estilos musicais permite que elas se reúnam em alguns espaços comuns, de alguns bailes.

Para a maioria das componentes, fazer parte do grupo, além de significar possibilidades de elaboração de suas identidades individuais e coletivas, representa a oportunidade de estabelecer contatos com outros grupos, constituindo, desse modo, novas sociabilidades. Os códigos identitários são específicos do grupo e se traduzem, por exemplo, nas coreografias exclusivas ensaiadas durante os finais de semana - esporadicamente isso ocorre durante a semana, pois a maioria trabalha e/ou estuda-. Os passos (re)inventados podem ser traduzidos como marcas registradas de determinados grupos de street dance. Assim, quando em contato com outros grupos, é possível observarmos essa disposição especial de cada grupo ser identificado através da ousadia, da inovação de passos coreográficos que têm a marca da criatividade juvenil. Isso pode ocasionar formas de domínio dos espaços e caracterizar determinados territórios no interior dos bailes. «Eles têm coreografias prontas. A maioria do grupo começa a fazer coreografia que a gente não sabe, pois a gente não ensaia com eles». Kelly faz essa observação para denunciar a dificuldade da presença feminina no baile de Padre Miguel onde um grupo - $\mathrm{O} \mathrm{JP}$ - garante a hegemonia masculina naquele lugar.

Embora pelo fato de tratar-se de grupos juvenis que têm as mesmas restrições no que diz respeito à falta de espaços para dançar - uma vez que o público é predominantemente composto por adultos-, o grupo masculino parece reproduzir esses mesmos mecanismos restritivos ao apresentar diversas coreografias nas quais os passos são realizados com giros de cabeça e rodopios no chão e, esses, as meninas não acompanham.

Se o grupo masculino «Jovens de Periferia» conquistou seu território em Padre Miguel, o mesmo não aconteceu com o Everybody Dance. Para Kelly, o espaço feminino nas danças populares urbanas está quase

me» que apresentei anteriormente. Mas serve, ainda, para demarcar as formas coreográficas apreendidas dos estilos que compõem a dança de rua. No caso do hip-hop, isso se torna redundante, pois a sua origem é nas ruas dos guetos afroamericanos de Nova York. 
sempre atrelado ao erotismo apelativo, à transformação da mulher em objeto de desejo, valorizado através do figurino e dos movimentos de grande apelo visual e sexual. Certamente, essa não é a proposta de seu grupo e isso pode representar restrições quanto às possibilidades de se apresentar em diversas localidades.

As diferenças de gênero, se em dado momento servem para delimitar espaços, em outro podem servir para a aproximação dos grupos e para a ampliação das redes de amizade tecidas através da dança. $O$ fato de ser um dos poucos grupos inteiramente femininos de «street Charme/street hip-hop» faz com que o Everybody Dance, aos poucos, tornese conhecido em uma cena cultural fortemente marcada pelos grupos masculinos. Isso desperta a curiosidade destes e resulta em alguns convites para a apresentação em diversos eventos realizados na cidade.

Por fim, é interessante ressaltar dois aspectos que podem sugerir uma contradição. Os bailes de Charme têm, de maneira geral, as suas pistas tomadas, majoritariamente, por mulheres e, no entanto, a maioria dos grupos de dança é composta por homens. Isso se deve ao fato destes terem incorporado elementos coreográficos do hip-hop bastante masculinizados. Além disso, dançar, para a cultura ocidental, tem uma forte relação com a feminilidade, pois quase sempre não é permitido ao homem ser sensual e delicado sem que a sua masculinidade seja posta em dúvida. Nesse sentido, parece bastante positiva a presença masculina nesses espaços, pois rompe, gradativamente, com o preconceito relacionado ao homem e à dança. «Eu acho que o street foi uma maneira de dançar [...] como homens. Mostra mais a masculinidade, dançam mais como homens do que o jazz, por exemplo». Kelly, assim como as outras jovens, considera a força e a virilidade como sendo componentes fundamentais para as coreografias dos rapazes, mas não dispensa toques de sensualidade, especialmente quando eles «dão uma reboladinha, levantam a blusa».

Diferenças à parte, as jovens sabem que, pelo fato de serem mulheres, há barreiras a serem rompidas, especialmente em espaços ocupados, predominantemente, pela presença masculina. Isso, certamente, não inviabiliza o fortalecimento das relações ampliadas pelo contato com outros grupos de rapazes que incentivam a presença das jovens nesses mesmos espaços.

Há dificuldades a serem superadas. A condição feminina pode estar reproduzida nesse contexto em que, assim como na sociedade, faltam espaços que garantam a igualdade de direitos e oportunidades para homens e mulheres, indistintamente. Além disso, a própria condição 
social é uma outra determinante para abalar as estruturas do grupo. Muitas vezes, a falta de dinheiro ameaça a permanência de algumas jovens no mesmo. E isso é uma das interdições a que está submetida a maioria dos jovens, especialmente os moradores dos bairros pobres do Rio de Janeiro.

Desse modo, o Charme - ou o New Charme - ou até mesmo qualquer expressão popular juvenil pode ser uma das poucas oportunidades para a efetivação de projetos culturais que permitam uma maior intervenção política desses jovens nos seus locais de origem. $\mathrm{O}$ grupo tem grande importância para canalizar essas energias necessárias para a organização de pautas específicas através das quais possa invidicar o direito de ser jovem na sua plenitude.

\section{CONCLUSÃo}

Uma das dificuldades encontradas para a ampliação dos espaços de Charme, da sua transformação em produto de consumo em larga escala, assim como do aumento de seus consumidores, parece ser a pouca visibilidade que este movimento possui. A sua quase ausência nos meios midiáticos tradicionais traduz o desconhecimento desses setores para as suas potencialidades como produto pronto para o consumo. Não há estatísticas de quantos jovens ou adultos estão ligados ao mundo, à cultura do Charme. Os espaços juvenis de consumo parecem estar, em sua maioria, preenchidos pelo funk e pelo hip-hop. Essas manifestações resultaram em diversos produtos que são apresentados como marcas identitárias de muitos grupos juvenis. Porém, é exatamente essa invisibilidade do Charme que se tornou um aspecto interessante da pesquisa. Se considerarmos o caráter dinâmico e muitas vezes, performático das culturas juvenis, entender os espaços do Charme como possibilidades de elaboração de identidades juvenis tornou-se um desafio, uma vez que este parece ocupar zonas periféricas e quase ocultas nas mídias.

A forte penetração do hip-hop nos espaços juvenis pode ser considerada como resultado da mundialização da cultura estadunidense e que, apesar de sua difusão em larga escala, não se constituiu em um processo homogêneo. Cada grupo juvenil, certamente, reinterpretará essa manifestação da cultura popular internacional juvenil de acordo com o seu contexto histórico, com a sua base material de existência e com as representações sociais com as quais organiza o seu cotidiano. Observamos, nesse caso, a importância e o poder de ressignificação 
que o local tem sobre o global. As múltiplas possibilidades e diferentes formas de aceso às manifestações culturais também irão influenciar as transformações do hip-hop em linguagem cultural juvenil.

Desse modo, pude notar a existência de laços de proximidade entre os grupos de Charme e hip-hop. Em todos os grupos juvenis com os quais eu mantive contato, foi possível observar que as duas manifestações estão fortemente presentes e entrelaçadas, a ponto de, algumas vezes, essas se confundirem nas falas desses jovens.

A pesquisa mostrou que há a gestação de um outro ritmo ou movimento cultural que é resultado de interconexões de jovens do hiphop nos espaços de Charme. Há, ainda, a identificação do jovem com a musicalidade do Charme e os estilos que marcam a cultura hip-hop. Como resultado desse processo, observamos o surgimento do New Charme. Por hora, sugeri esse nome a fim de facilitar a compreensão daquilo que tenho percebido e que ainda não conseguimos verbalizar - apesar de claramente identificado pelos charmeiros - tal qual fez Corello, quando deu o nome ao Charme, em 1980.

O New Charme tem proporcionado o aumento do número de jovens nos bailes que até então, eram freqüentados, majoritariamente, por adultos. Estes, por sua vez, olham aqueles com a mesma desconfiança com que parecem ter sido olhados quando foram jovens precursores dos bailes de Charme. Não conseguem perceber que o processo de hibridização do qual resultou o surgimento do Charme se (re)atualiza. Da mesma forma que, para que o Charme nascesse, foi preciso que a onda discotéque tivesse sucumbido, podemos refletir a respeito da necessidade do declínio das formas tradicionais do Charme. Entretanto, isso não significa o seu desaparecimento, mas a sua reinterpretação, dando lugar às novas expressões musicais daí decorrentes e marcadas pela presença juvenil.

O saudosismo que parece tomar conta de alguns adultos ao relembrarem a chamada época de ouro dos bailes não é suficiente para garantir a sua existência. Os bailes de flash back e mid back têm, exatamente, essa função, ou seja, a de manter viva a memória, a lembrança dos momentos felizes em que tiveram o direito de ser jovens em seu tempo. Mesmo nesses bailes é possível observar a presença de jovens não afinados com o movimento hip-hop, por exemplo. São jovens que também podem apontar para outros caminhos pelos quais o Charme pode seguir. Entre eles, podemos identificar que é possível pensar na continuação do Charme longe dos olhos da mídia. Há espaços de continuidade existentes nas comunidades, nos bairros pobres e 
que estão ocupados por sujeitos que pertencem a uma juventude diversa daquela que possui visibilidade resultante da transformação do hiphop em produto de consumo.

Negar a presença dos jovens nos espaços de Charme em nome de uma cultura tradicional moderna pode colocar em risco a sua própria continuidade. É através desses jovens que os diferentes processos, seja de transformação, seja de continuação estarão se concretizando. A presença juvenil pode significar, acima de tudo, a renovação e a efetiva consolidação dos bailes de Charme como espaços de elaboração de identidades.

Os jovens que encontrei nos bailes tradicionais também são amantes desse estilo musical e este forte vínculo está estabelecido em função das experiências vivenciadas com os seus familiares. Esses jovens aprenderam desde cedo a ouvir e a gostar do Charme através da influência de seus parentes que ouviam —e ouvem - música negra diariamente, em seus lares.

É importante ressaltar que o fato de duas formas de cultura juvenil urbana estarem em contato em um mesmo espaço revelou fortes relações de alteridade e respeito mútuo entre os seus participantes. A tolerância está constantemente presente e, apesar da demarcação de territórios específicos, com fronteiras invisíveis, constitui-se em marca que possibilita a convivência tranqüila de diferentes juventudes naqueles espaços.

Manifestações culturais juvenis urbanas, o funk e o hip-hop parecem ter as mesmas origens musicais do Charme. A procura de espaços próprios de visibilidade fez com que cada um desses estilos trilhasse o seu caminho e fosse apropriado de diferentes maneiras pelos jovens. Assim, enquanto o funk foi estigmatizado por «produzir uma conduta, supostamente inconseqüente, que glorifica a delinqüência, o hip-hop pode ser considerado perigoso pela postura radical e hiperpolitizada, por produzir um discurso que incentiva o racismo, a intolerância, a revolta violenta das minorias» (Hershmann, 2000:192). Por outro lado, o Charme, longe de ser alienado ou alienante, produz uma estética pautada em comportamentos que valorizam a amizade, o companheirismo, a camaradagem, o amor. Suas letras cantam, geralmente, a afetividade e a paixão. Suas coreografias favorecem a sensualidade — sem apologia ao sexo gratuito - o fortalecimento das relações de companheirismo e de grupo.

Apesar da situação de exclusão e suposta passividade em que vive a maioria dos charmeiros, esta não utiliza os mesmos instrumentos 
de denúncia e protesto comuns aos outros grupos. Os charmeiros também estão preocupados com a miséria, por exemplo. Mas estão partindo para práticas e ações efetivas que permitam o exercício da participação como agentes de mudanças sociais. Esses grupos juvenis estão propondo alternativas que partem do campo cultural para desenvolver atividades comunitárias, por exemplo. Acreditam, dentre outras coisas, que podem contribuir para reduzir a presença de jovens no mundo do tráfico oferecendo a eles a dança como alternativa.

É nos diversos espaços destinados aos bailes de Charme que encontramos jovens que, sem negar os conflitos e as desigualdades sociais que impregnam as suas vidas, são capazes de se autoorganizarem através da música e da dança. Pode ser que exista certa alienação entre os seus valores e aqueles das gerações que os antecedem. Portanto, podemos identificar relações intergeracionais conflituosas que se constituem como uma das marcas estruturantes desse espaço plural que é o movimento Charme. São diferentes modos de ver e entender o mundo em que vivem, pois estão sendo jovens em seu tempo, em contextos sociais diferentes dos mais velhos. Isso pode apontar para diversas interpretações e possibilidades de ser jovem na atualidade. Uma destas é expressa pelo jovem no Charme como prática coletiva que pode determinar diversidade de papéis e/ou múltiplas identidades e que, necessariamente, não tem tendência à violência nem tampouco à alienação, mas à elaboração de formas organizativas que proporcionem relações mais afetivas e preocupadas em alterar o contexto social em que vivem, alterando, desse modo, a situação juvenil.

RIO DE JANEIRO (BRASIL), MARZO 2005

RECIBIDO: ABRIL 2005

ACEPTADO: JUNIO 2005

\section{REFERÊNCIAS BIBLIOGRÁFICAS}

CANClini, NÉSTOR GARCía (2000): Culturas híbridas. São Paulo: EDUSP.

Gomes, NiLma L. (2000): «Trajetórias escolares, corpo negro e cabelo crespo: reprodução de estereótipos e/ou ressignificação cultural?». Trabalho apresentado na XXV Reunião da ANPED. Caxambu, Minas Gerais, Mimeo.

Herschmann, Michael (2000): O funk e o hip-hop invadem a cena. Rio de Janeiro: UFRJ.

KEMP, KÊNIA (1993): «Grupos de estilo jovens: o 'rock underground' e as práticas (contra)culturais dos estilos 'punk' e 'trash' em São Paulo». Dissertação de Mestrado. Campinas: Unicamp. 
Magnani, José Guilherme C. (1998): Festa no pedaço: cultura popular e lazer na cidade. São Paulo: Hucitec.

Ribeiro, Leila B.; J. S. Rosario e M. S. Chicanel (2002): «O Charme ao som de seus programas de rádio». Rio de Janeiro: Morpheus. Revista Eletrônica em Ciências Humanas, Ano 01, Nº1. UNIRIO/CEAD.

SARLO, BEATRIZ (2000): Cenas da vida pós-moderna: intelectuais, arte e videocultura na Argentina. Rio de Janeiro: UfRJ ( $2^{\mathrm{a}}$ ed.).

SPOSITO, MARILIA (1999): «Algumas hipóteses sobre as relações entre movimentos sociais, juventude e educação». Trabalho apresentado na XXII Reunião Anual da ANPED, Mimeo. 